\title{
Enhanced, unaltered and impaired nitric oxide-mediated endothelium-dependent relaxation in experimental diabetes mellitus: importance of disease duration
}

\author{
G.M. Pieper \\ Department of Transplant Surgery, Medical College of Wisconsin, Milwaukee, USA
}

\begin{abstract}
Summary Long-term diabetes mellitus is characterized by impaired endothelium-dependent relaxation. In contrast, there is limited information on endothelial function in the early stages of the disease. In this study, we evaluated endothelial function ex vivo at early, intermediate and later stages of streptozotocin (STZ)-induced diabetes mellitus. We also evaluated the contribution of various endothelium-derived vasoactive factors at these stages of disease. In aortic rings contracted with norepinephrine, endotheliumdependent relaxation to acetycholine was increased at $24 \mathrm{~h}$ following injection with streptozotocin compared with controls, normal after 1 and 2 weeks of disease or impaired at 8 weeks of disease. Endothelium-independent relaxation to nitroglycerin was unaltered at all stages. The enhanced relaxation at $24 \mathrm{~h}$ was mimicked in rings from alloxan-induced diabetic rats. Acute exposure of normal rings to streptozotocin in vitro caused no perturbation in acetylcholine-
\end{abstract}

stimulated relaxation. Enhanced relaxation in diabetic rings at $24 \mathrm{~h}$ persisted in the presence of either indomethacin or tetraethylammonium. Acetylcholineinduced relaxation was blocked in both control and diabetic rings using L-nitroarginine but not by aminoguanidine. This suggests that the increased response was mediated by enhanced constitutive nitric oxide (NO). These studies show a triphasic response of increased, unaltered and impaired endothelium-dependent relaxation within the same model but dependent on the duration of disease. These studies could reconcile previous conflicting data in the literature and account for the observations of increases in tissue blood flow seen in early stages of experimental and human diabetes mellitus. [Diabetologia (1999) 42: 204-213]

Keywords Endothelium, nitric oxide, diabetes mellitus, L-nitroarginine, endothelium-dependent hyperpolarizing factor.
Substantial evidence exists for impaired endothelium-dependent relaxation of both conduit and resistance arteries from experimental animal models of diabetes mellitus [1-5]. Previous studies examining endothelium-dependent relaxation to acetylcho-

Received: 21 August 1998 and in revised form: 7 October 1998

Corresponding author: Dr. G. M. Pieper, Department of Transplant Surgery, Medical College of Wisconsin, Froedtert Memorial Lutheran Hospital, 9200 West Wisconsin Avenue, Milwaukee, WI 53226, USA

Abbreviations: NO, Nitric oxide; STZ, streptozotocin; iNOS, inducible nitric oxide synthase; cNOS, constitutive nitric oxide synthase; EDHF, endothelium-derived hyperpolarizing factor; TEA, tetraethylammonium. line or bradykinin due to streptozotocin (STZ)-induced diabetes have shown varying times of onset of impairment including: 1 week in intestinal arterioles [6], 2 weeks in hindquarters but not renal or femoral arteries [7], 3 weeks in cremaster muscle arterioles [8], 4-6 weeks in mesenteric arteries [9, $10]$ or 4 weeks in aorta $[11,12]$. The variance in onset of endothelial dysfunction might be explained by experimental conditions including the type of artery or the type of vasodilator examined (e.g. histamine) in a given artery preparation [7, 8, 12, 13]. Defects in endothelium-dependent relaxation which are specific for decreased nitric oxide (NO) bioactivity or NO production have not always been determined but have been confirmed and discussed [5]. 
Table 1. Diabetogenic condition

\begin{tabular}{lccc}
\hline Group & $n$ & $\begin{array}{l}\text { Glucose } \\
(\mathrm{mmol} / \mathrm{l})\end{array}$ & $\begin{array}{l}\text { Glycated } \\
\text { haemoglobin } \\
(\%)\end{array}$ \\
\hline 24 h & 9 & $4.7 \pm 0.5$ & n.d. \\
Control & 7 & $15.8 \pm 1.3^{\mathrm{a}}$ & n.d. \\
STZ-diabetic & & & \\
1 week & 8 & $4.5 \pm 0.5$ & $4.5 \pm 0.6$ \\
Control & 11 & $22.4 \pm 0.9^{\mathrm{a}}$ & $8.4 \pm 0.7^{\mathrm{a}}$ \\
STZ-diabetic & & & \\
2 week & 4 & $4.4 \pm 0.4$ & $4.6 \pm 0.7$ \\
Control & 9 & $22.0 \pm 1.1^{\mathrm{a}}$ & $14.7 \pm 1.6^{\mathrm{a}}$ \\
$\begin{array}{l}\text { Diabetic } \\
\text { 8 week }\end{array}$ & & & \\
Control & 9 & $3.4 \pm 0.2$ & $4.1 \pm 0.2$ \\
Diabetic & 8 & $22.0 \pm 0.7^{\mathrm{a}}$ & $14.3 \pm 0.4^{\mathrm{a}}$ \\
\hline
\end{tabular}

${ }^{a} P<0.01$ vs age-matched control, n.d. $=$ not determined

Table 2. Time-dependent change in vascular contractile response to norepinephrine

\begin{tabular}{lrll}
\hline Group & $n$ & Maximum $(g)$ & $\mathrm{pD}_{2}$ \\
\hline 24 h & & $1.73 \pm 0.16$ & $6.98(7.09-6.87)$ \\
Control & 9 & $1.13 \pm 0.10^{\mathrm{a}}$ & $6.65(6.71-6.59)^{\mathrm{a}}$ \\
STZ-diabetic & 7 & & \\
1 week & & $1.93 \pm 0.17$ & $7.08(7.18-6.97)$ \\
Control & 8 & $1.71 \pm 0.14$ & $6.96(7.04-6.89)$ \\
STZ-diabetic & 11 & & \\
2 week & & & $6.64(6.71-6.58)$ \\
Control & 4 & $1.41 \pm 0.05$ & $6.63(6.70-6.56)$ \\
STZ-diabetic & 9 & $1.78 \pm 0.22$ & \\
8 week & & & $6.71(6.79-6.63)$ \\
Control & 9 & $1.52 \pm 0.12$ & $6.70(6.79-6.61)$ \\
Diabetic & 8 & $1.46 \pm 0.19$ & \\
\hline
\end{tabular}

${ }^{\mathrm{a}} p<0.05$ vs age-matched controls

Despite, the overwhelming evidence of impaired endothelium-dependent relaxation in diabetes mellitus, there are sporadic reports of enhanced [14-16] or unaltered [17-20] endothelium-dependent relaxation. One consideration for the absence of defects in conduit artery studies after several weeks of diabetes mellitus might include methodological factors such as the use of helical strips [17] or the possibility of cross-over effects due to multiple drug evaluation in the same preparation [20]. Interestingly, the findings from diabetic arteries for enhanced and decreased function are remarkably similar to other discordant data showing enhanced $[21,22]$ or impaired $[23,24]$ intracellular $\mathrm{Ca}^{2+}$ signalling or NO production or both by isolated endothelial cells exposed to increased glucose concentrations.

There has not been any direct study to reconcile the potential reasons for the different findings in diabetic arteries. In addition, the nature of the enhanced endothelium-dependent relaxation in diabetic arteries, such as the production of various vasoactive factors contributing to this enhanced response, has not been determined. Because some of the findings of in-

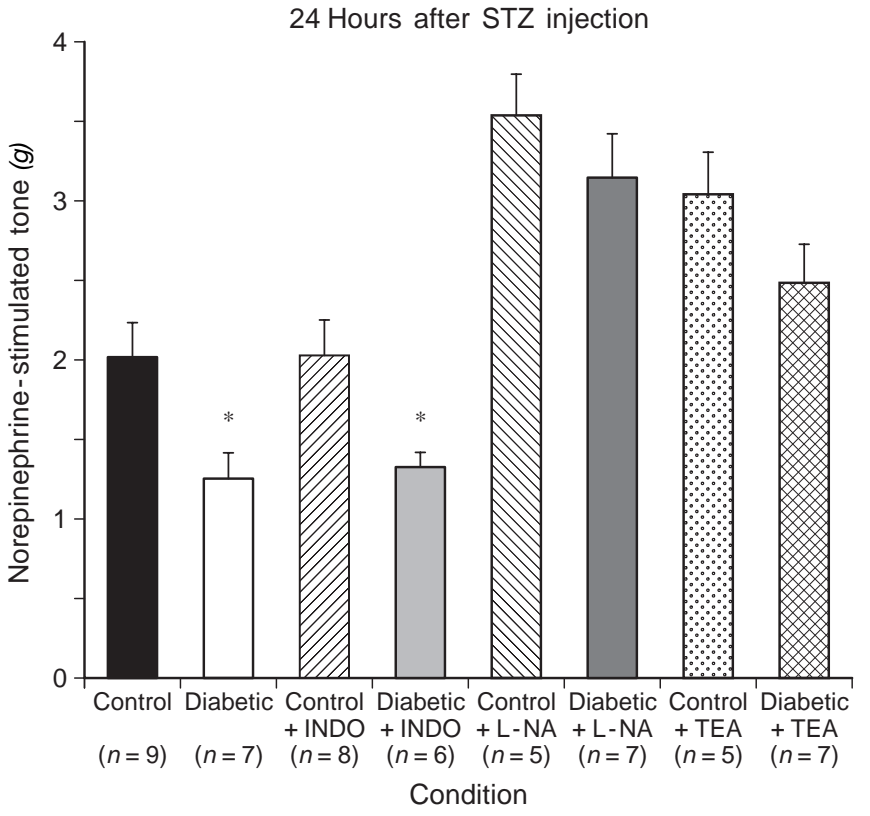

Fig. 1. Effects of various treatments in vitro on contractile responses to $1 \mu \mathrm{mol} / \mathrm{l}$ norepinephrine in aorta with intact endothelium of 24-h STZ diabetic rats. INDO, indomethacin; L-NA, L-nitroarginine; TEA, tetraethylammonium. ${ }^{*} p<0.01$ vs corresponding control

creased endothelium-dependent relaxation were reported in diabetic animals with a short duration of the disease, we hypothesized that diabetes might increase relaxation in early stages and decrease relaxation at later stages of the disease. Although we acknowledge that this scenario has been proposed previously [25], there has not been any study to verify this hypothesis.

Thus, the purpose of this study was to examine whether there are fluctuating changes in endothelium-dependent relaxation at early, intermediate compared with later stages of disease. A secondary purpose was to examine the nature of the alteration in endothelium-dependent relaxation by evaluating the contribution of NO compared with other potential vasoactive factors which might account for these variations.

\section{Materials and methods}

Diabetes was induced by tail-vein injection of $55 \mathrm{mg} / \mathrm{kg} \mathrm{STZ} \mathrm{in}$ male Sasco, Sprague-Dawley rats (age 10-11 weeks), which had been anaesthetized with an intraperitoneal injection of $100 \mathrm{mg} / \mathrm{kg}$ ketamine. A subgroup for the 24-h studies was injected with $70-90 \mathrm{mg} / \mathrm{kg}$ alloxan to achieve a level of glycaemia comparable to the STZ study. Hyperglycaemia was verified at 24 or $48 \mathrm{~h}$ by using an ExacTech glucometer and test strips (Medisense, Cambridge, Mass., USA). After verifying hyperglycaemia, diabetic and age-matched control rats were housed for 1 day or 1, 2 and 8 weeks.

At the end of each period, animals that had not been fasted were anaesthetized with $65 \mathrm{mg} / \mathrm{kg}$ pentobarbital. Blood was 

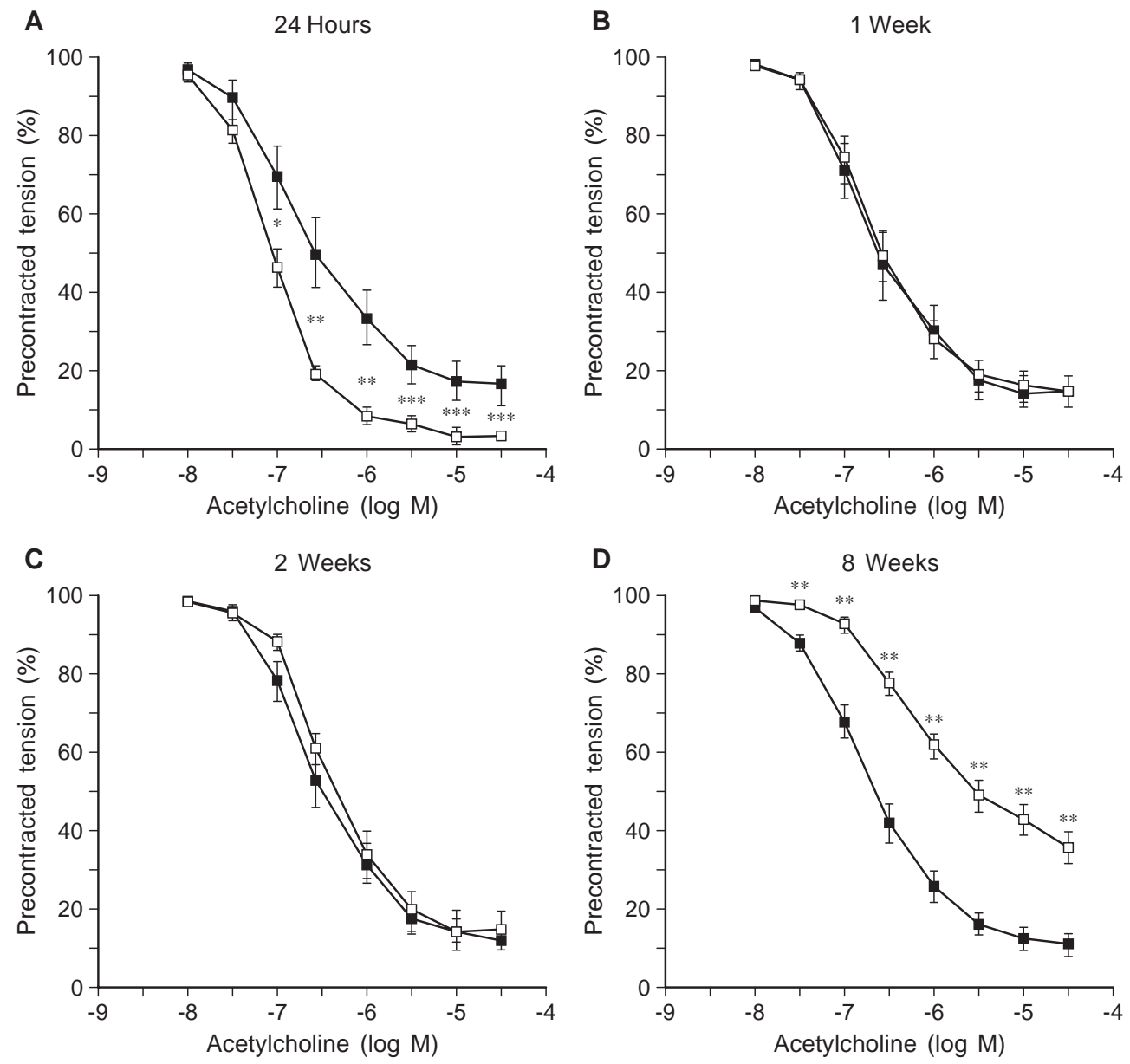

Fig. 2 A,B,C,D. Concentration-dependent relaxation to acetylcholine in aortic rings after durations of STZ-induced diabetes mellitus; A 24 h control $n=9$, diabetic $n=7$. B 1 week, control $n=8$, diabetic $n=11$. C 2 weeks, control $n=4$, diabetic $n=9$. D 8 weeks, control $n=9$, diabetic $n=8$. $* p<0.025$ and $* * p<0.01$ and $* * * p<0.001$ vs age-matched controls. - $\square$-, control; - $\square$-, diabetic

Table 3. Acetylcholine-stimulated relaxation ex vivo in aortic rings of 24-h streptozotocin-induced diabetic rats

\begin{tabular}{lccc}
\hline Group & $n$ & Maximum & $\mathrm{pA}_{2}(95 \% \mathrm{CI})$ \\
\hline $\begin{array}{l}\text { Control } \\
\text { Streptozotocin }\end{array}$ & 7 & $84 \pm 5 \%$ & $6.47(6.59-6.35)$ \\
$\begin{array}{l}\text { Control + TEA } \\
\text { Streptozotocin + TEA }\end{array}$ & 7 & $65 \pm 13 \%^{\mathrm{a}}$ & $7.01(7.07-6.95)^{\mathrm{a}}$ \\
$\begin{array}{l}\text { Control + } \\
\text { indomethacin }\end{array}$ & 8 & $84 \pm 6 \% \%^{\mathrm{a}}$ & $6.50(6.60-5.93)$ \\
$\begin{array}{l}\text { Streptozotocin }+ \\
\text { indomethacin }\end{array}$ & 6 & $101 \pm 3 \%^{\mathrm{a}}$ & $6.60(7.04-6.37)$ \\
$\begin{array}{l}\text { Control + } \\
\text { L-nitroarginine }\end{array}$ & 5 & $-1 \pm 1 \%$ & \\
$\begin{array}{l}\text { Streptozotocin }+ \\
\text { L-nitroarginine }\end{array}$ & 7 & $1 \pm 3 \%$ & \\
$\begin{array}{l}\text { Control + } \\
\text { aminoguanidine }\end{array}$ & 5 & $74 \pm 7 \%$ & $6.17(6.29-6.04)$ \\
$\begin{array}{l}\text { Streptozotocin }+ \\
\text { aminoguanidine }\end{array}$ & 7 & $98 \pm 3 \%)^{\mathrm{a}}$ & $6.89(6.98-6.81)^{\mathrm{a}}$ \\
\hline
\end{tabular}

${ }^{\mathrm{a}} p<0.05$ vs control response

taken for the determination of glucose and total glycosylated haemoglobin. Because of the short duration of increased glucose concentration, glycosylated haemoglobin was not measured in animals injected $24 \mathrm{~h}$ previously with either STZ or alloxan. Blood glucose was determined by glucometer. Total glycosylated haemoglobin was measured using commercial kits (Sigma Diagnostics, St. Louis, Mo., USA).

The descending thoracic aorta was removed and cleaned of fat and connective tissue. Aortae were sectioned into 3-mm rings and mounted in tissue baths containing Krebs bicarbonate buffer. Rings were stretched to an optimal resting tension of $2.0 \mathrm{~g}$. Isometric tension was recorded by using a Gould TA6000 recorder (Gould Instruments, Valley View, Ohio, USA) and Radnoti force-displacement transducers and amplifiers (Radnoti, Monrovia, Calif., USA).

After $1 \mathrm{~h}$ or equilibration, rings were contracted to increasing concentrations of norepinephrine, washed and equilibrated. Rings were then contracted to a submaximum concentration of norepinephrine (usually $1 \mu \mathrm{mol} / \mathrm{l}$ ) to achieve equipotent contraction followed by addition of cumulative concentrations of acetylcholine or nitroglycerin to evaluate endothelium-dependent or endothelium-independent relaxation, respectively. Only one vasodilator was used for each ring preparation. In some experiments, the nitroglycerin studies were done in rings in which the endothelium had been removed by gently rubbing the luminal surface.

To evaluate the nature of changes in endothelium-dependent relaxation, relaxation was assessed in untreated rings compared with rings pretreated with either $10 \mu \mathrm{mol} / 1$ indomethacin (a cyclooxygenase inhibitor), $1 \mathrm{mmol} / \mathrm{l}$ tetraethylammonium (an inhibitor of $\mathrm{Ca}^{2+}$-activated $\mathrm{K}^{+}$channels), 

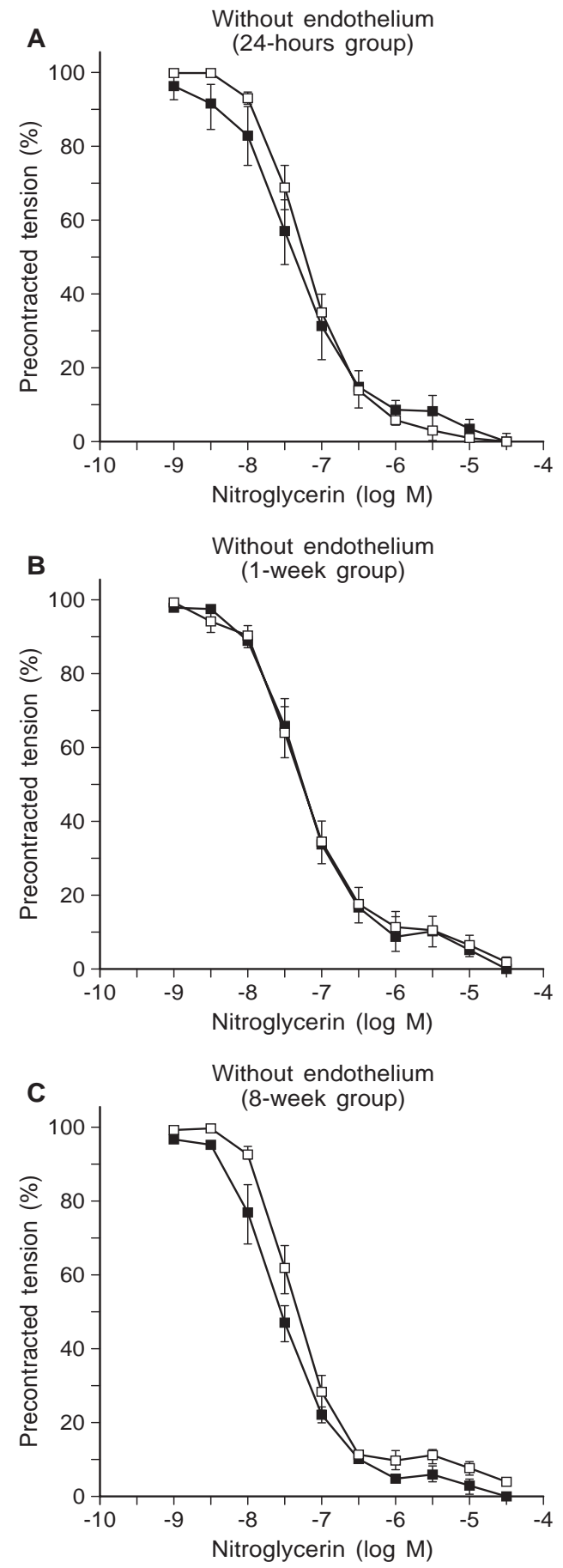

Fig.3 A,B,C. Concentration-dependent, endothelium-independent relaxation to nitroglycerin in aortic rings without endothelium derived from rats after injection with STZ at indicated times. A $24 \mathrm{~h}$, control $n=9$, diabetic $n=7$. B 1 week, control $n=7$, diabetic $n=10$. C 8 weeks, control $n=6$, diabetic $n=8$. $-\square-$, control; $-\square-$, diabetic

$100 \mu \mathrm{mol} / \mathrm{l}$ aminoguanidine (an inhibitor of inducible NO synthase, iNOS) or $100 \mu \mathrm{mo} / \mathrm{l}$ L-nitroarginine (an inhibitor of constitutive NO synthase, cNOS).

To evaluate direct effects of exposure of arteries to diabetogenic agents on evaluation of endothelium-dependent relaxation, rings were incubated with $0.5,1.0$ and $1.5 \mathrm{mmol} / \mathrm{l} \mathrm{STZ}$

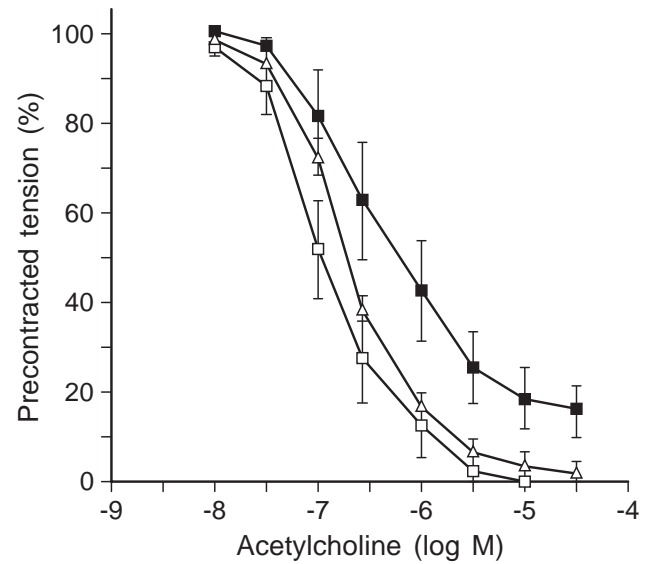

Fig. 4. Comparison of endothelium-dependent relaxation to acetylcholine of aortic rings in the presence of indomethacin at $24 \mathrm{~h}$ following treatment with the diabetogenic agents, STZ $(\square)$ or alloxan $(\triangle)$ vs. control $(\square) . p<0.01$ for both STZ and alloxan group vs. control

or alloxan for $2 \mathrm{~h}$ followed by rinsing. These conditions were chosen based upon: (a) choosing a range or higher than the maximum plasma concentration $(<0.3 \mu \mathrm{mol} / \mathrm{l})$ achieved after injection of $200 \mathrm{mg} / \mathrm{kg} \mathrm{STZ}$ into mice [26]; (b) the half-life of drug in vivo has been estimated to be in the range of $15 \mathrm{~min}$ [27] and (c) the radiolabelled STZ in plasma is absent by $1 \mathrm{~h}$ after drug injection [28].

Most chemicals and drugs were obtained from Sigma (Sigma Chemical, St. Louis, Mo., USA) including: streptozotocin, alloxan, norepinephrine, acetylcholine, indomethacin, tetraethylammonium, L-nitroarginine and aminoguanidine. Nitroglycerin was obtained from Parke-Davis (Parke-Davis/Warner Lambert, Morris Plains, N. J., USA).

Data were calculated as means \pm SEM and analysed by repeated-analysis of variance followed by Student-NeumanKeuls test for multiple mean comparisons or paired $t$ or unpaired $t$ tests for comparisons of two group means, where appropriate. To satisfy statistical significance, a $p$ value less than 0.05 was chosen.

\section{Results}

Blood glucose was raised at each point in time after STZ-injection relative to nondiabetic controls (Table 1). Glycosylated haemoglobin was raised partially by 1 week and plateaued by 2 weeks of disease.

In aortic rings, the maximum contraction and reactivity $\left(\mathrm{pD}_{2}\right)$ to norepinephrine was reduced at $24 \mathrm{~h}$ after STZ injection but was not altered after 1, 2 and 8 weeks compared with age-matched controls (Table 2). Within the 24-h group, indomethacin did not alter contractile tone elicited by $1 \mu \mathrm{mol} / \mathrm{l}$ norepinephrine in either control or diabetic rings (Fig. 1). In contrast, contractile tone increased in both control and diabetic rings after incubation with either tetraethylammonium or L-nitroarginine. Despite the decreased contractile tone in untreated diabetic compared with untreated control rings, there was no difference in contraction between control and diabetic 

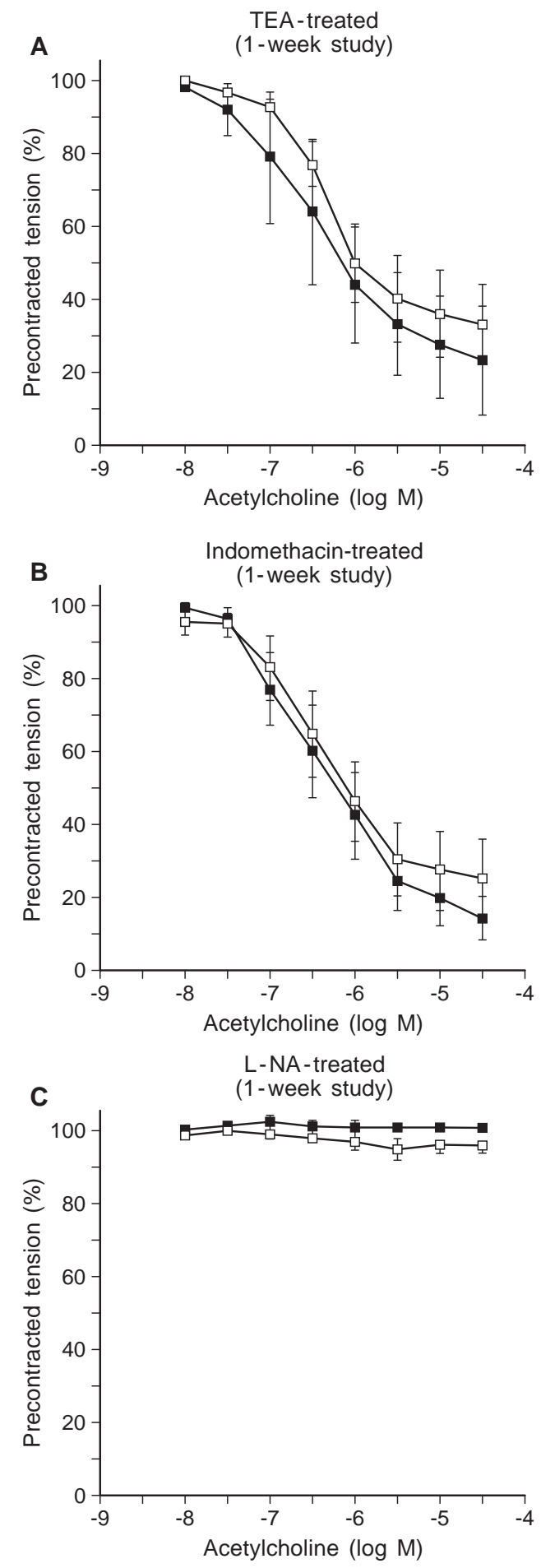

Fig. 5 A,B,C. Treatment with $\mathbf{A}$ tetraethylammonium (TEA; control $n=6$, diabetic $n=8$ ) or $\mathbf{B}$ indomethacin (control $n=8$, diabetic $n=9$ ) in vitro fails to alter the lack of differences in acetylcholine-induced relaxation response of aortic rings of 1-week diabetic rats. $\mathbf{C}$ The cNOS inhibitor, L-nitroarginine (L-NA; control $n=5$, diabetic $n=6$ ), eliminates relaxation to acetylcholine in each group. - $\square$-, control; - $\square$-, diabetic
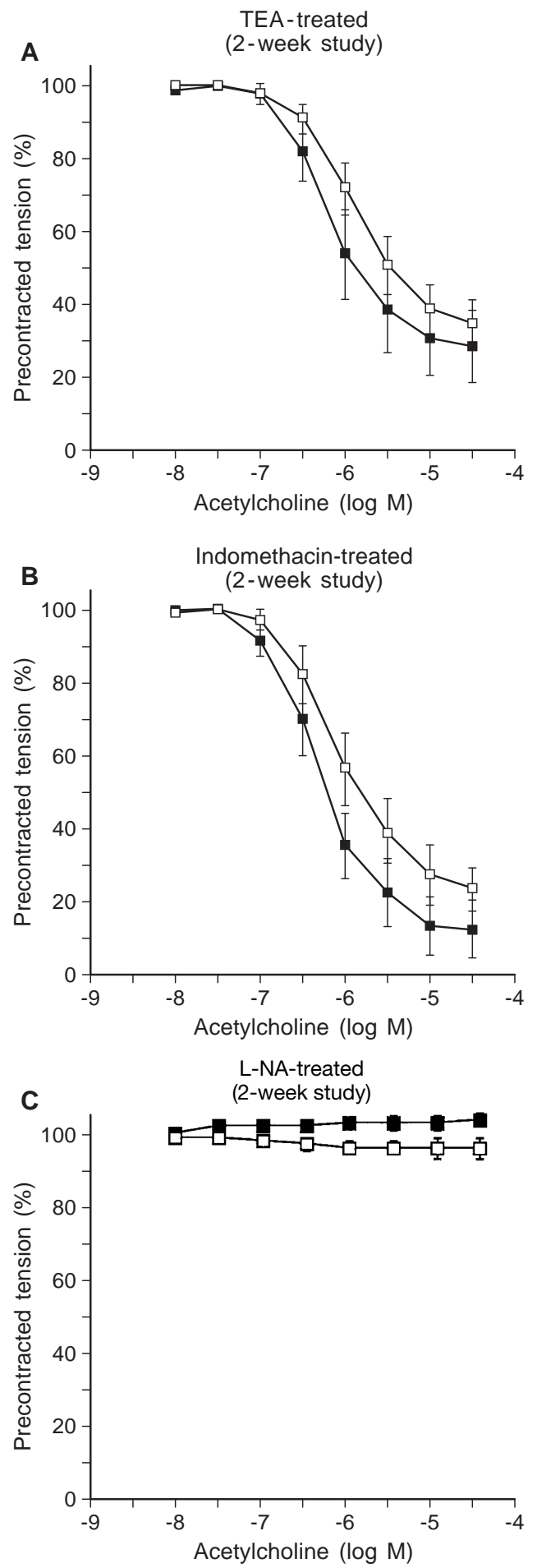

Fig.6 A,B,C. Treatment with $\mathbf{A}$ tetraethylammonium (TEA; control $n=4$, diabetic $n=9$ ) or $\mathbf{B}$ indomethacin (control $n=4$, diabetic $n=9$ ) in vitro fails to alter the lack of differences in acetylcholine-induced relaxation response of aortic rings of 2-week diabetic rats. $\mathbf{C}$ The cNOS inhibitor, L-nitroarginine (L-NA; control $n=4$, diabetic $n=9$ ), eliminates relaxation to acetylcholine in each group. - $\square$-, control; - $\square-$, diabetic 

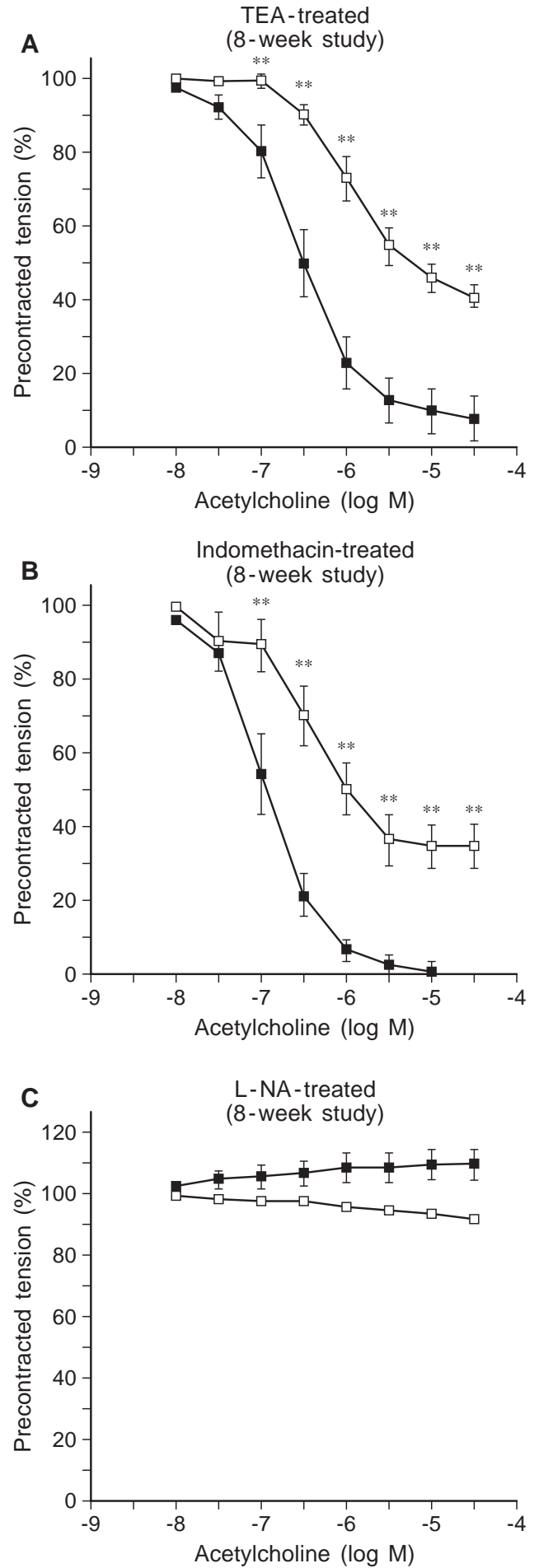

Fig. 7 A,B,C. Impaired endothelium-dependent relaxation in aortic rings from 8 -week diabetic rats vs age-matched control rasts conducted in the absence or presence of tetraethylammonium (TEA; control $n=8$, diabetic $n=8$ ) B indomethacin (control $n=5$, diabetic $n=7$ ) or $\mathbf{C}$ L-nitroarginine (L-NA, control $n=9$, diabetic $n=8)$. ${ }^{*} p<0.01$ vs treated controls. $-\square$-, control; - $\square-$, diabetic groups which were treated with either tetraethylammonium or L-nitroarginine. In additional pair-matched studies, removal of the endothelium caused an increase in contractile tone. In the 24-h group, this increase was greater in rings from diabetic $(1.13 \pm 0.10$ $g$ vs $2.53 \pm 0.09 g$, with and without endothelium, respectively, $p<0.01)$ compared with controls $(1.73 \pm 0.17 \mathrm{~g}$ vs $2.21 \pm 0.18 \mathrm{~g}$, with and without endothelium, respectively, $p<0.01)$.

For the endothelium-dependent relaxation studies, the norepinephrine concentration was varied, if necessary, to produce equipotent contraction. As the diabetic group showed decreased reactivity to norepinephrine, the norepinephrine concentration in the 24-h control group only was varied resulting in $72 \pm 2 \%$ and $72 \pm 3 \%$ of maximum response for control and diabetic groups, respectively. Endotheliumdependent relaxation to acetylcholine was enhanced in diabetic rings at $24 \mathrm{~h}$ after STZ was given (Fig. 2). In contrast, acetylcholine-stimulated relaxation after 1 and 2 weeks was not altered relative to age-matched controls, but was impaired at 8 weeks of disease. In each case, relaxation to nitroglycerin was not altered (Fig. 3). The increased endothelium-dependent relaxation to acetylcholine at $24 \mathrm{~h}$ after STZ injection was mimicked in aortic rings in the absence (not shown) or presence of indomethacin (Fig.4) derived from animals treated for a similar time with another diabetogenic agent, alloxan.

Relaxation to acetylcholine in diabetic rings in rats $24 \mathrm{~h}$ post-injection with STZ remained enhanced after incubation in vitro with either indomethacin, tetraethylammonium or aminoguanidine compared with similar reponses in treated-control rings (Table 3 ). In contrast, incubation with L-nitroarginine completely eliminated acetylcholine-stimulated relaxation in both control and diabetic rings.

In the 1- and 2-week groups, the lack of difference in acetylcholine-stimulated relaxation between control and diabetic rings remained despite treatment with either tetraethylammonium or indomethacin (Figs. 5 and 6). In addition, pretreatment with L-nitroarginine eliminated acetylcholine-stimulated relaxation in both control and diabetic rings.

The impaired relaxation to acetylcholine in aortic rings after 8 weeks of diabetes persisted during incubation with either indomethacin, tetraethylammonium (Fig. 7) or aminoguanidine (not shown). Furthermore, L-nitroarginine abolished relaxation in control rings and reduced relaxation by nearly $90 \%$ in diabetic rings.

To examine potential direct effects of exposure of aorta to diabetogenic agents on endothelial function, aortic rings from normal rats were exposed to increasing concentrations of either STZ or alloxan. Prior exposure to either STZ (Fig.8) or alloxan (Fig.9) failed to alter endothelium-dependent relaxation to acetylcholine. 

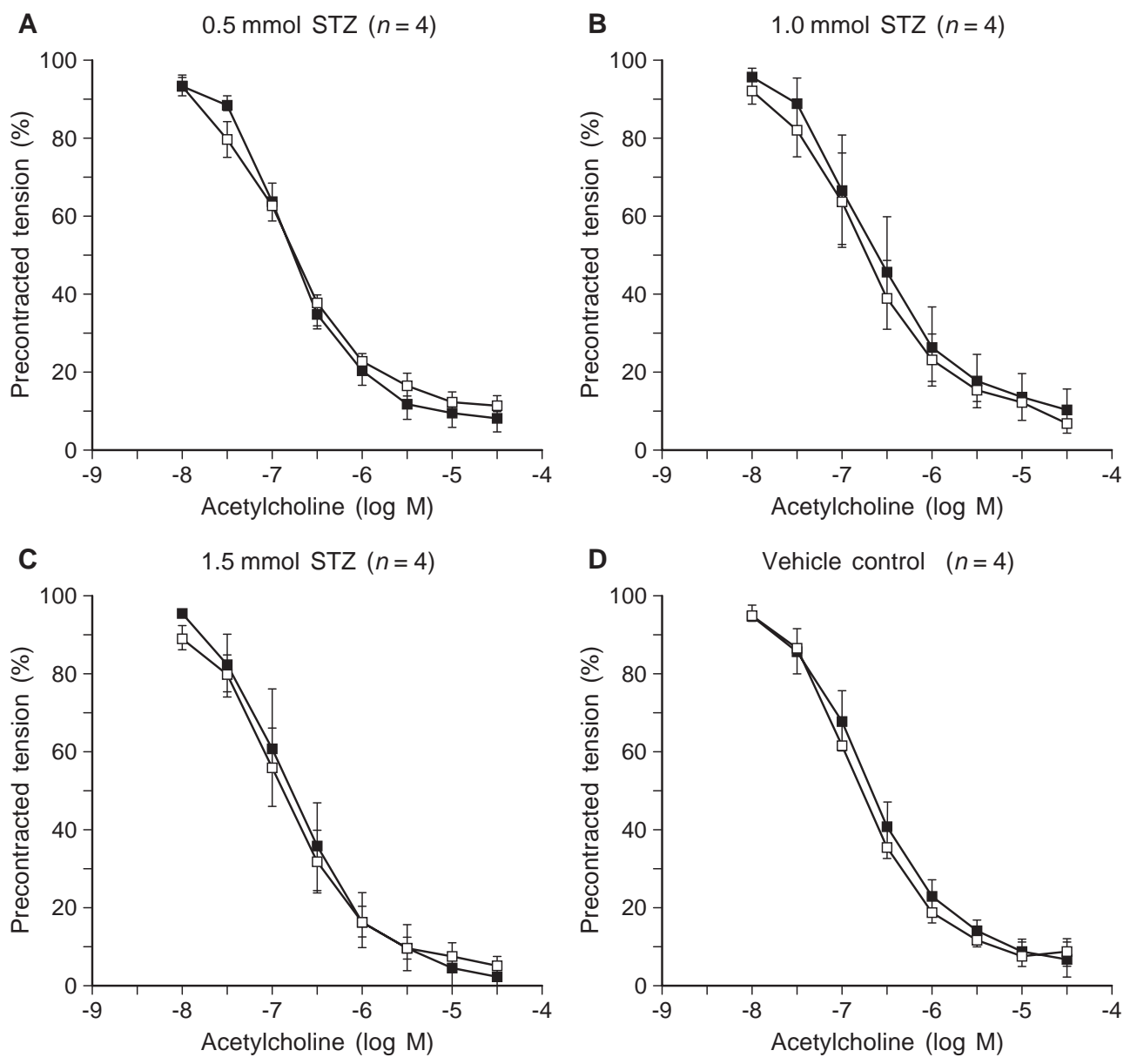

Fig. 8. Concentration-dependent relaxation to acetylcholine in normal aortic rings precontracted with $0.3 \mu \mathrm{mol} / 1$ norepinephrine before and after exposure ex vivo to increasing concentrations of STZ (A $0.5 \mathrm{mmol} \mathrm{STZ,} \mathrm{B} 1.0 \mathrm{mmol} \mathrm{STZ,} \mathrm{C} 1.5 \mathrm{mmol}$ STZ; - $\square$ - before STZ, - $\square$ - After STZ) vs citrate vehicle buffer (D - $\square$ - before citrate; $-\square$ - after citrate)

\section{Discussion}

Despite considerable evidence for impaired endothelium-dependent relaxation following long-term diabetes mellitus, there was a need for a comprehensive temporal study including examination of endothelial function at early time periods. Our study shows an increase in endothelium-dependent relaxation early in diabetes which is followed by a reversion phase in which relaxation is normal and subsequently followed by a final phase of impaired relaxation. The finding of increased endothelium-dependent relaxation of aorta early in diabetes is similar to the increased relaxation observed in the mesenteric artery in the early stages of diabetes which reverts back to normal with a longer duration of the disease [29]. Our finding of a phase of increased endothelium-dependent relaxation to acetylcholine in aorta and the

findings of others of increased endothelium-dependent relaxation in mesenteric or renal artery $[6,29]$ suggest that this property occurs in both conduit and resistance arteries.

We considered the possibility of a peripheral vascular effect of STZ per se on endothelial function in aorta as STZ can be a NO donor under certain conditions $[30,31]$. We conclude that the increased endothelium-dependent relaxation in aorta of STZ-induced diabetic rat is not unique to this model which might be independent of effects of diabetes for several reasons. Firstly, similar findings of enhanced endothelium-dependent relaxation were observed elsewhere in mesentery arteries of STZ-diabetic rats [29]. Secondly, these results were reproduced in aortic rings from alloxan-induced diabetic rats. Thirdly, acute exposure in vitro to peak physiological or higher concentrations of either alloxan or STZ failed to alter endothelium-dependent relaxation in control arteries.

A limitation of previous studies which have shown either enhanced, unaltered or impaired endotheliumdependent relaxation is that these evaluations focused on a single point in time following onset of disease and which cannot take into account any fluctuating changes during the course of the disease. Our finding of a normal phase of acetylcholine-stimulated 

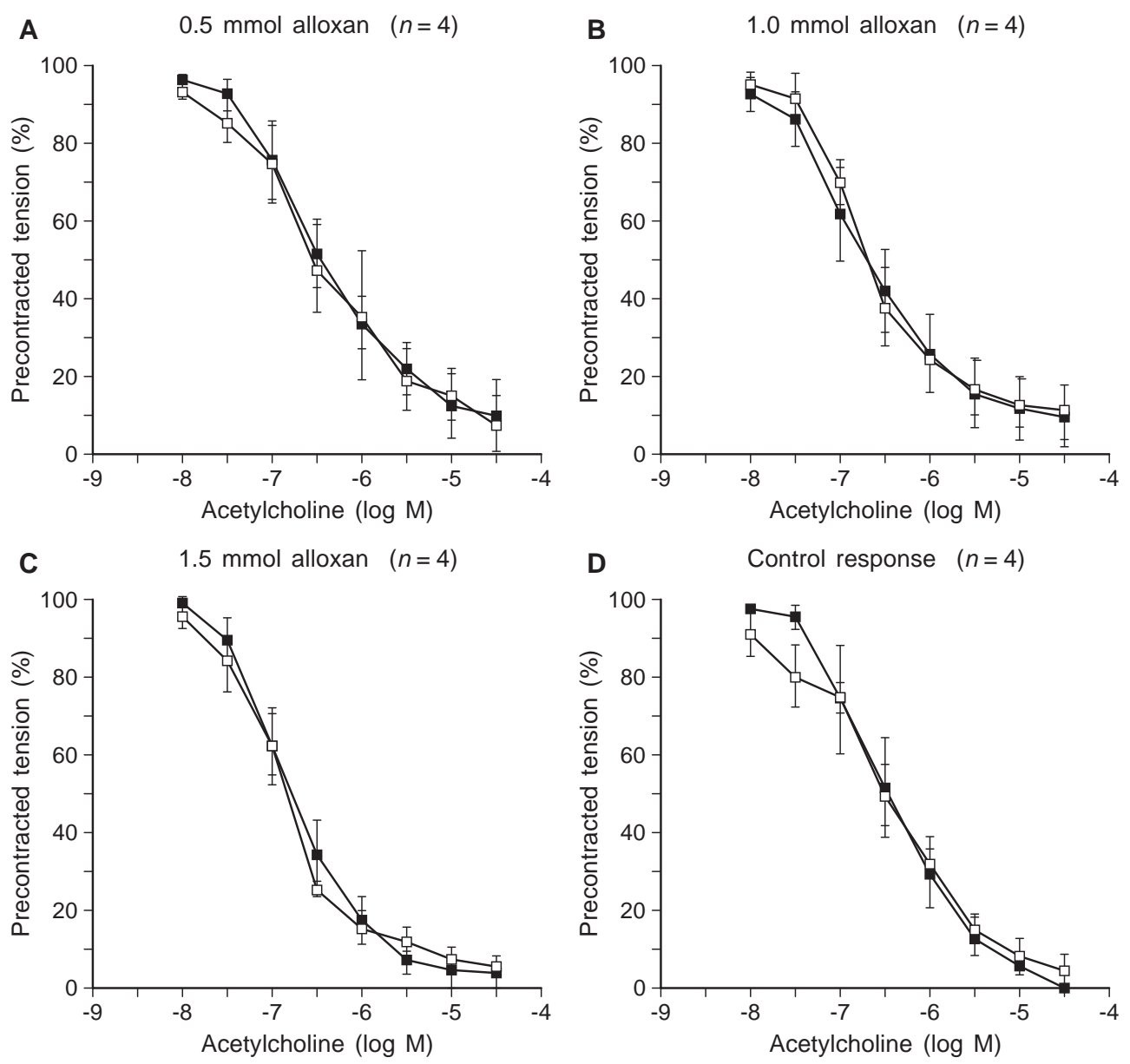

Fig.9. Concentration-dependent relaxation to acetylcholine in normal aortic rings precontracted with $0.3 \mu \mathrm{mol} / 1$ norepinephrine before and after exposure ex vivo to increasing concentrations of alloxan (A $0.5 \mathrm{mmol}$ alloxan, B $1.0 \mathrm{mmol}$ alloxan, C 1.5 mmol alloxan; - $\mathbf{-}$ - before alloxan, - $\square$ - after alloxan) $\mathbf{D}$ control response - $\square$ - first challenge; - $\square$ - second challenge

relaxation in an intermediate time period interspersed between enhanced and impaired endothelium-dependent relaxation would help to reconcile the previous observation of normal endothelial function in aorta of diabetic animals of 2-3 week duration [18]. More importantly, our new observations may help to reconcile the discrepant data in the literature for all three phenomena (i.e. enhanced, unaltered or decreased relaxation). Our study shows that each phenomenon can be observed in the same model depending on the duration of disease examined.

Another important facet of this investigation is the evaluation of possible factors or lack of factors responsible for altered responses (both increased and decreased) at various stages of disease. For example, both increased and decreased vasodilator prostaglandins have been reported in various diabetic arteries [32]. We have previously shown that indomethacin

fails to alter the impaired endothelium-dependent relaxation seen at 8 weeks of disease [33]. This is confirmed in this study. This does not preclude some effect at earlier stages. There are reports of increased prostacyclin production in mesenteric arteries of early stages of diabetes (i.e. 3 week) [34] but whether this is unique to this vascular bed is not known. Our findings using indomethacin argue against increased vasodilator prostanoids in the increased acetylcholine-stimulated relaxation observed in aortic rings of rats at $24 \mathrm{~h}$ of disease. Furthermore, our study also agrees with the studies conducted in renal artery [15] and mesenteric artery [29] of STZ-diabetic rats which showed that the increase in endothelium-dependent relaxation at early stages of diabetes persists in the presence of indomethacin. These findings suggest that vasoactive prostanoids do not contribute to the enhanced response. That L-nitroarginine blocks relaxation to acetylcholine in both control and diabetic groups and indomethacin has no effect on acetylcholine-induced relaxation suggests that this rat aortic preparation is conducive to evaluation of diabetes-induced changes in NO-mediated, endothelium-dependent relaxation.

Accordingly, we considered the possibility that either increased endothelium-derived hyperpolarizing factor (EDHF) or NO was increased under these con- 
ditions. L-nitroarginine prevents the relaxation to acetylcholine in both control and diabetic rings at $24 \mathrm{~h}$ after injection of rats with STZ suggesting that the enhanced relaxation is mediated predominantly via increased NO production. This conclusion is consistent with our recent finding that long-term treatment with a NO scavenger prevents the development of diabetes-induced endothelial dysfunction [35].

The role of enhanced EDHF or hyperpolarization in early stages of diabetes is not conclusive. One study has examined membrane potentials in diabetic arteries and found impaired endothelium-dependent hyperpolarization in diabetic mesenteric arteries; however, these studies were in animals with 8-12 weeks of diabetes [36]. Another study of longterm diabetes mellitus concluded that there was no deficit in EDHF in diabetic aorta using potassium channel blockers such as tetraethylammonium [37]. Similar results using this antagonist were obtained in our 8-week diabetic model.

Note that tetraethylammonium caused a greater shift in sensitivity to acetylcholine-stimulated relaxation in diabetic rings but no increased change in maximum relaxation compared with controls in the 24-h study. This suggests the possibility of enhanced reactivity of tetraethylammonium-sensitive, NO-dependent relaxation in this group which would be consistent with recent findings for hyperpolarization and increased cGMP production in gastric glands, a few days after onset of disease in the alloxan-diabetic rabbit [38].

The reasons for increased arterial NO production early in diabetes is not known. Previous studies using endotoxin treatment of normal arteries or endothelial cells to increase iNOS have shown decreased production of NO from cNOS [39]. Furthermore, prior long-term exposure to $\mathrm{NO}$ donor agents also has been shown to decrease cNOS production of NO [40]. Although there is no evidence to date for increased iNOS in arteries of early or later stages of diabetes, there is evidence for increased cNOS activity based upon arginine-to-citrulline conversion in cell homogenates [41], or cNOS mRNA [unpublished results; 42] and cNOS protein [42] in isolated human or mammalian endothelial cells exposed to short periods of raised glucose concentrations. Our results following challenges with aminoguanidine ex vivo are consistent with the lack of iNOS expression in diabetic arteries at either early or late stages of disease. Nevertheless, the precise mechanism of the relation between enhanced production of NO from endothelial cNOS and the subsequent impaired NO-mediated, endothelial-dependent relaxation in diabetic arteries remains to be determined.

In summary, this study is the first to show a triphasic response of endothelial function at different stages of diabetes mellitus. These findings could reconcile the diverse findings reported in the literature.
Acknowledgements. This work was supported, in part, by Grant no. HL47072 from the National Institutes of Health, Heart and Lung Institute.

\section{References}

1. Pieper GM, Gross GJ (1991) Endothelial dysfunction in diabetes. In: Rubanyi GM (ed) Cardiovascular Significance of Endothelium-Derived Vasoactive Factors. Futura Publishing, Mount Kisco, New York, pp 223-249

2. Kamata N, Miyata N, Abiru T, Kasuya Y (1992) Functional changes in vascular smooth muscle and endothelium of arteries during diabetes mellitus. Life Sci 50: 1379-1387

3. Cohen RA (1993) Dysfunction of vascular endothelium in diabetes mellitus. Circulation 87 [Suppl V]:V67-V76

4. Poston L, Taylor PD (1995) Endothelium-mediated vascular function in insulin-dependent diabetes mellitus. Clin Sci 88: 245-255

5. Pieper GM (1998) Review of alterations in endothelial nitric oxide production in diabetes. Protective role of arginine on endothelial dysfunction. Hypertension 31: 1047-1060

6. Lash JM, Bohlen HG (1991) Structural and functional origins of suppressed acetylcholine vasodilation in diabetic rat intestinal arterioles. Circ Res 69: 1259-1268

7. Kiff RJ, Gardiner SM, Compton AM, Bennett T (1991) Selective impairment of hindquarters vasodilator responses to bradykinin in conscious Wistar rats with streptozotocininduced diabetes mellitus. Br J Pharmacol 103: 1357-1362

8. Alsip NL, Schuschke DA, Miller FN (1996) Microvascular responses in the skeletal muscle of the diabetic rat. J Lab Clin Med 128: 429-437

9. Diederich D, Skopec J, Diederich A, Dai FX (1994) Endothelial dysfunction in mesenteric arteries of diabetic rat: role of free radicals. Am J Physiol 266 (Heart Circ Physiol 35):H1153-H1161

10. Wang SP, West MW, Dresner LS, Fleishhacker JF, Distant DA, Mueller CM, Wait RB (1996) Effects of diabetes and uremia on mesenteric vascular reactivity. Surgery 120: 328-336

11. Bucala R, Tracey KJ, Cerami A (1991) Advanced glycosylation products quench nitric oxide and mediate defective endothelium-dependent vasodilatation in experimental diabetes. J Clin Invest 87: 432-438

12. Orie NN, Aloamaka CP, Iyawe VI (1993) Duration-dependent attenuation of acetylcholine- but not histamine-induced relaxation of the aorta in diabetes mellitus. Gen Pharmacol 24: 329-332

13. Tanz RD, Chang KSK, Weller TS (1989) Histamine relaxation of aortic rings from diabetic rats. Agents Actions 28: $1-8$

14. White RE, Carrier GO (1986) Supersensitivity and endothelium dependency of histamine-induced relaxation in mesenteric arteries isolated from diabetic rats. Pharmacology 33: 34-38

15. Bhardwaj R, Moore PK (1988) Increased vasodilator response to acetylcholine of renal blood vessels from diabetic rats. J Pharm Pharmacol 40: 739-742

16. Altan VM, Karasu C, Özüari A (1989) The effects of type-1 and type-2 diabetes on endothelium-dependent relaxation in rat aorta. Pharmacology Biochemistry and Behavior 33: $519-522$

17. Wakabayashi I, Hatake K, Kimura N, Kaksishita E, Nagai K (1987) Modulation of vascular tonus by the endothelium in experimental diabetes. Life Sci 40: 643-648 
18. Mulhern M, Docherty JR (1989) Effects of experimental diabetes on the responsiveness of rat aorta. Br J Pharmacol 97: 1007-1012

19. Murray P, Pitt B, Webb RC (1994) Ramipril prevents hypersensitivity to phenylephrine in aorta from streptozotocin-induced diabetic rats. Diabetologia 37: 664-670

20. Head RJ, Longhurst PA, Panek RL, Stitzel RE (1987) A contrastine effect of the diabetic state upon contractile responses of aortic preparations from the rat and rabbit. $\mathrm{Br}$ J Pharmacol 91: 275-286

21. Graier WF, Wascher TC, Lackner L, Toplak H, Krejs GJ, Kukovetz WF (1993) Exposure to elevated D-glucose concentration modulates vascular endothelial cell vasodilatory responses. Diabetes 42: 1497-1505

22. Sobrevia L, Nadal A, Yudilevich DL, Mann GE (1996) Activation of $\mathrm{L}$-arginine transport $\left(\right.$ system $\mathrm{y}^{+}$) and nitric oxide synthase by elevated glucose and insulin in human endothelial cells. J Physiol (Lond) 490.3: 775-781

23. Pieper GM, Dondlinger LA (1997) Glucose elevations alter bradykinin-stimulated intracellular calcium accumulation in cultured endothleial cells. Cardiovasc Res 34: 169-178

24. Salameh A, Dhein S (1998) Influence of long-term D-glucose exposure and long-term-b-blocker treatment on intracellular calcium concentrations of porcine aortic endothelial cells. Diabetes 47: 407-413

25. Wascher TC, Graier WF, Bahadori B, Toplak H (1994) Time course of endothelial dysfunction in diabetes mellitus. Circulation 90: 1109

26. Anderson T, Schein PS, McMenamin MG, Cooney DA (1974) Streptozotocin diabetes. Correlation with extent of depression of pancreatic islet nicotinamide adenine dinucleotide. J Clin Invest 54: 672-677

27. Adolphe AB, Glasofer ED, Troetel WM, Weiss AJ (1977) Preliminary pharmacokinetics of streptozotocin, an antineoplastic antibiotic. J Clin Pharmacol (July):379-388

28. Johansson EB, Tjälve H (1978) Studies on the tissue-disposition and fate of $\left[{ }^{14} \mathrm{C}\right]$ streptozotocin with special reference to the pancreatic islets. Acta Endocrinologica 89: 339-351

29. Heygate KM, Davies J, Holmes M, James RFL, Thurston $\mathrm{H}$ (1996) The effect of insulin treatment and of islet transplantation on the resistance artery function in the STZ-induced diabetic rat. Br J Pharmacol 119: 495-504

30. Kwon NS, Lee SH, Choi CS, Kho T, Lee HS (1994) Nitric oxide generation from streptozotocin. FASEB J 8: 529-533

31. Kröncke K-D, Kolb-Bachofen V (1996) Commentary: streptozotocin is not a spontaneous NO donor. Free Radic Res 24: 77-80
32. Pieper GM (1991) Alterations in reperfusion-stimulated prostacyclin release by the diabetic heart. In: Nagano M, Dhalla NS (eds) The Diabetic Heart. Raven Press, New York, pp 465-483

33. Pieper GM, Langenstroer P, Siebeneich W (1997) Diabeticinduced endothelial dysfunction in rat aorta: role of hydroxyl radicals. Cardiovasc Res 34: 145-156

34. Fujii K, Soma M, Huang YS, Manku MS, Horrobin DF (1986) Increased release of prostaglandins from the mesenteric vascular bed in streptoztocotin diabetes. Prog Lipid Res 25: 499-501

35. Pieper GM, Dembny K, Siebeneich, W (1998) Long-term treatment in vivo with NOX-101, a scavenger of nitric oxide, prevents diabetes-induced endothelial dysfunction. Diabetologia 41: 806-812

36. Fukao M, Hattori Y, Kanno M, Sakuma I, Kitabatake A (1997) Alterations in endothelium-dependent hyperpolarization and relaxation in mesenteric arteries from streptozotocin-induced diabetic rats. $\mathrm{Br} \mathrm{J}$ Pharmacol 121: 1383-1391

37. Endo K, Abiro T, Machida H, Kasuya Y, Kamata, K (1995) Endothelium-derived hyperpolarizing factor does not contribute to the decrease in endothelium-dependent relaxation in the aorta of streptozotocin-induced diabetic rats. Gen Pharmacol 26: 149-153

38. Contreras R, Fuentes O, Mann GE, Sobrevia L (1997) Diabetes and insulin-induced stimulation of L-arginine transport and nitric oxide synthesis in rabbit isolated gastric glands. J Physiol 498: 787-796

39. Myers PR, Wright WF, Tanner MA, Adams HR (1992) EDRF and nitric oxide production in cultured endothelial cells: direct inhibition by E. coli endotoxin. Am J Physiol 262 (Heart Circ Physiol 31): H710-H718

40. Bult H, DeMeyer GRY, Jordaens FH, Herman AG (1991) Long-term exposure to exogenous nitric oxide may suppress its endogenous release and efficacy. J Cardiovasc Pharmacol 17 [Suppl 3]: S79-S82

41. Graier WF, Simecek S, Kukovetz WR, Kostner GM (1996) High D-glucose-induced changes in endothelial $\mathrm{Ca}^{2+} /$ EDRF signaling are due to generation of superoxide anions. Diabetes 45: 1386-1395

42. Cosentino F, Hishikawa K, Katusic ZS, Lüscher TF (1997) High glucose increases nitric oxide synthase expression and superoxide anion generation in human aortic endothelial cells. Circulation 96: 25-28 